\title{
Patient Experience on International Safety Goals Using Adapted Net Promoter Score - NPS-S
}

\section{Salvador Gullo Neto ${ }^{1 *}$ and Philip Greiner ${ }^{2}$}

${ }^{1}$ Assistant Professor at School of Medicine - PUCRS, Visiting Scholar at School of

Nursing - SDSU and Affiliate Scholar at Langston Center for Innovation on Quality

and Safety - VCU, USA

${ }^{2}$ Professor and Director at School of Nursing - SDSU, USA

*Corresponding Author: Assistant Professor at School of Medicine - PUCRS,

Visiting Scholar at School of Nursing - SDSU and Affiliate Scholar at Langston

Center for Innovation on Quality and Safety - VCU, USA.
Received: November 11, 2020

Published:

(C) All rights are reserved by Salvador Gullo

Neto and Philip Greiner.

\begin{abstract}
Objective: Assessing patients' perception of safety issues in health institutions is a challenge. The use of simple tools to quantify this perception would bring important benefits to the healthcare sector. Our aim is to describe the use of a traditional market tool for the evaluation of customer experience and satisfaction, the Net Promoter Score (NPS), to assess patients' perception of the practice of international safety goals in health institutions. Methods: Through a mobile application, we present to patients the basic concepts of the 6 international patient safety goals of the World Health Organization and at the end of each instruction, we request their evaluation, using the NPS tool with questions adapted to the patient safety scenario. We call this adapted NPS of Net Promoter Safety Score, NPS-S.

Results: During a 6 months period, 352 users download the app in more than 94 different healthcare services in Brazil and made 1719 evaluations about their safety experience, with the average NPS-S of 45\%, that means a score in the improvement zone.

Conclusions: patient engagement is essential for the reduction of adverse events. In this study, the Net Promoter Safety Score adapted to patient safety issues, the NPS-S, was easy to understand by users and may be a very useful tool to translate patient perceptions into manageable data, helping health institutions to develop the culture of safety.

Keywords: Net Promoter Score; Patient safety; Patient Experience; Patient Assesment; Patient Engagement
\end{abstract}

\section{Introduction}

Medical errors are still one of the major challenges to be overcome by the health sector. According to data from the Patient Safety Movement Foundation, more than 200,000 patients die each year in American hospitals from adverse events [1]. The Center for Disease Control and Prevention (CDC) points out adverse events as the third cause of death in American hospitals, right behind the deaths from cardiac causes and cancer [2]. In Brazil, the situation is similar. According to the II Anuário da Segurança Assistencial Hospitalar, hospital mortality associated with adverse events was more than 235,000 deaths in 2017 [3].
Many initiatives were developed to mitigate this situation. Intensive training of healthcare teams, the use of technologies, and the development of the culture of safety for healthcare institutions are the tools that have enabled us to considerably improve the results in recent years [4].

Patient engagement is a strategy that always appears in the list of recommendations from experts that works for the development of patient safety, but the effective participation of patients and family members in their self-care is still quite limited and sometimes not promoted in healthcare institutions [5]. Among the various reasons for that, we mention the lack of practical tools that allow 
the measurement of the users' experience of the health system in relation to international patient safety goals.

Net Promoter Score is a widely known tool in the market and was introduced by Heicheld in 2003 in order to measure the degree of customer loyalty with companies from all sectors, bringing reflections of their experience and satisfaction [6]. As this tool is easily understood by users and is already widely used in the healthcare market to assess patient satisfaction with non-clinical aspects, we considered the possibility of adapting it to assess the patient's safety experience.

Our aim is to describe the use of a traditional market tool for the evaluation of customer experience and satisfaction, the Net Promoter Score, to assess patients' perception of the practice of international safety goals in health institutions.

\section{Methods}

Through a free mobile application, SAFETY4ME ${ }^{\circ}$, available for IOS and Android platforms, we introduce to users the 6 international patient safety goals in a colloquial language, allowing easy understanding of the subject for the average person. The app uses gamification techniques within the storytelling in order to strengthen patient engagement during its use. Users check in, identifying the institution in which they are receiving treatment and access a trail where they receive information pertinent to international patient safety protocols.

At the end of each trail users are invited to report their experience with regard to the storytelling presented and to evaluate whether, during their treatment at that health institution, the patient safety recommendations presented were effectively applied.

To access user perception, we used the Net Promoter Score (NPS) tool adapted to issues related to patient safety. Net Promoter Score (NPS) is a tool that aims to measure the degree of loyalty of the customers of companies of any segment, bringing reflections of their experience and satisfaction. It was conceived in 2003 by Fred Heinchheld in his article The One Number You Need [6].

Through an analog-visual scale, users playfully expresses their perception of the issue on screen.

To track healthcare costumer perceptions of the patient safety protocols, we made a modification on the NPS questions, adjusting for patient safety inquiries.



Figure 1

Example: Based on fall prevention instructions, would you recommend this healthcare provider to someone who needs care?.

We call this adaptation the Net Promoter Score of Patient Safety, or simply NPS-S.

Based upon user response, we calculated the NPS-S using the following formula:

NPS-S $=\%$ Promoters $-\%$ Detractors

The results obtained could range between $-100 \%$ to $100 \%$ and this percentage represents different zones according to this graphic.

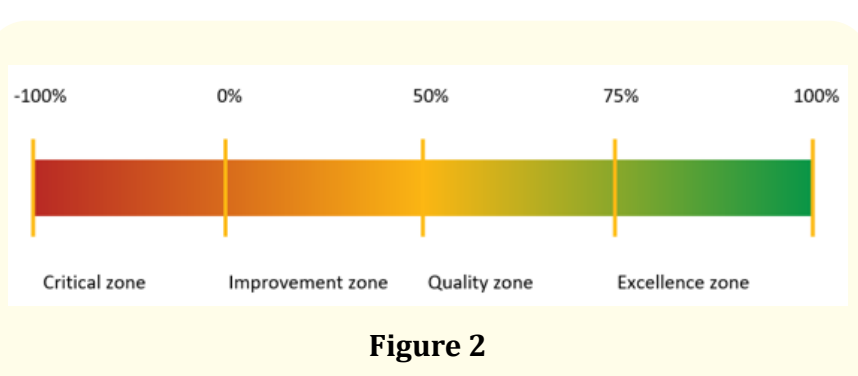

During the first half of 2020, we released the app on social media in Brazil and started collecting data sent by users in a Microsoft business intelligence system - Power $\mathrm{BI}^{\circ}$. This information was consolidated by institution, region of Brazil and international safety goal.

\section{Results}

From February to July 2020, we promoted the SAFETY4ME app on social networks in order to boost its use by users of the health system while receiving care or after their treatment. In this period of 6 months, 352 organic downloads were made in several cities of Brazil, as illustrated in the map below. 


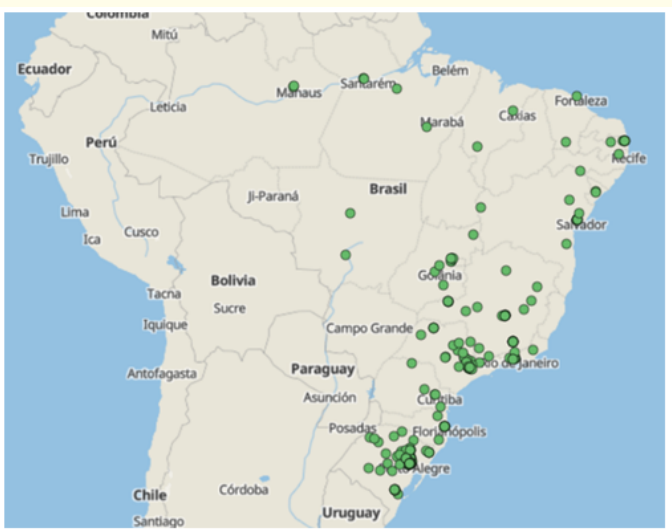

Figure 3

Because of the General Data Protection Law, the application did not ask user's identification, contact or any other sensitive data. During the application check-in process, users only informed on which institution they were receiving treatment and their perceptions about the execution of safety goals in this institution.

These 352 downloads generated 1719 evaluations from 94 health institutions in Brazil, mostly hospitals (73.4\%).

\begin{tabular}{|l|c|}
\hline n of downloads & 352 \\
\hline n of evaluations & 1719 \\
\hline n of institutions & $94(100 \%)$ \\
\hline Hospitals & $69(73.4 \%)$ \\
\hline Clinics & $25(26.6 \%)$ \\
\hline
\end{tabular}

Table 1: Sample.

The overall evaluation obtained through the consolidation of all user evaluations of the health system indicated an NPS-S of $45 \%$ in the improvement zone.

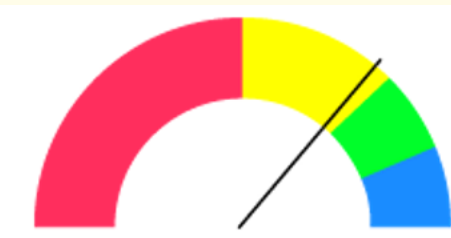

NPS - S 45\% - Improvement zone

1719 evaluations

94 institutions

Figure 4
Those evaluations can be separated by the 6 international patients safety goals. Below you can find users perception regarding each protocol.



Figure 5

\begin{tabular}{|ll|}
\hline 1. & Abertta Contagem \\
\hline 2. & Alice Fischer Cirurgiã Plástica e Cranio-maxilo-facial - RS \\
\hline 3. & ARS CVRANDI - SP \\
\hline 4. & CAI - Centro de Atendimento Integrado - RS \\
\hline 5. & CAPSi- GHC Centro de Atenção Psicossocial à Infância e à \\
& Adolescência - RS \\
\hline 6. & Centro de Saúde São Francisco - MG \\
\hline 7. & Centro Diagnóstico Cardiológico - Unimed Birigui - SP \\
\hline 8. & Centro Médico Brooklin - SP \\
\hline 9. & Centro Médico Osasco - SP \\
\hline 10. & Clínica Aura Odontologia e Saúde - RS \\
\hline 11. & Clínica Boghos Unidade Sul - CE \\
\hline 12. & Clinoson - RS \\
\hline 13. & COR-Centro de Oncologia e Radioterapia - RS \\
\hline 14. & HCOR \\
\hline 15. & Hospital Aliança \\
\hline 16. & Hospital Ana Costa \\
\hline 17. & Hospital Antônio Targino \\
\hline 18. & Hospital Banco de Olhos \\
\hline 19. & Hospital Beneficente Nossa Senhora de Fátima \\
\hline 20. & Hospital Cardio Pulmonar \\
\hline 21. & Hospital da Bahia \\
\hline 22. & Hospital de Caridade e Beneficência de Cachoeira do Sul \\
\hline
\end{tabular}


23. Hospital de Clínicas Caieiras

24. Hospital de Clínicas de Passo Fundo

25. Hospital de Clínicas de Porto Alegre

26. Hospital de Pronto Socorro

27. Hospital Delphina Rinaldi Abdel Aziz

28. Hospital Dia e Pronto Atendimento Unimed Vale do Sinos

29. Hospital Dilson Godinho

30. Hospital Divina Providência

31. Hospital Dona Balbina

32. Hospital Ernesto Dornelles

33. Hospital Estadual Vila Alpina

34. Hospital Estrela

35. Hospital Evangélico Goiano

36. Hospital Evangélico Sorocaba

37. Hospital Fêmina

38. Hospital Florianópolis

39. Hospital Geral de Novo Hamburgo

40. Hospital Geral de Parauapebas HGP Manoel Evaldo Benevides Alves

41. Hospital Governador Celso Ramos

42. Hospital Humanitas Unimed

43. Hospital Madre Teresa

44. Hospital Mãe de Deus

45. Hospital Maria Auxiliadora

46. Hospital Moinhos de Vento

47. Hospital Monte Sinai

48. Hospital Municipal Nossa Senhora da Conceição

49. Hospital Nossa Senhora da Conceição

50. Hospital Nossa Senhora da Oliveira (HNSO)

51. Hospital Novo Atibaia

52. Hospital Prontomed

53. Hospital Regina

54. Hospital Regional Santa Lúcia

55. Hospital Samaritano SP

56. Hospital Santa Paula

57. Hospital São Bernardo

58. Hospital São Camilo - Unidade Ipiranga

59. Hospital São João Evangelistas Unidade 2

60. Hospital São José

61. Hospital São Lucas Copacabana

62. Hospital São Lucas da PUCRS
63. Hospital São Paulo - PI

64. Hospital São Paulo - SP

65. Hospital São Sebastião Mártir

66. Hospital Tacchini

67. Hospital Unimed Araxá

68. Hospital Unimed BH

69. Hospital Unimed Erechim

70. Hospital Unimed Governador Valadares

71. Hospital Unimed Juiz de Fora

72. Hospital Unimed Nordeste - RS

73. Hospital Unimed Noroeste/RS

74. Hospital Unimed Pelotas

75. Hospital Unimed Petrópolis

76. Hospital Unimed Poços de Caldas

77. Hospital Unimed Vale do Caí

78. Hospital Universitário Ciências Médicas

79. Hospital Vitor Lang Caçapava do Sul

80. HUCAM - Hospital Universitário Cassiano Antônio de Moraes (Hospital das Clínicas)

81. INCOR - Instituto do Coração de Caldas Novas / Hospital e Maternidade Nossa Senhora Aparecida

82. IOVALE - Instituto de Olhos do Vale - SP

83. IVI SALVADOR MEDICINA REPRODUTIVA S/A - BA

84. Núcleo Unifácil - Porto Alegre - RS

85. Posto de Saúde Marina - RS

86. Pronto Atendimento Unimed Porto Alegre - Canoas - RS

87. Psiconeuro - PB

88. Rejomal - Caruarú

89. Santa Casa de Misericórdia de Juiz de Fora

90. Sobam

91. Suksteris - Núcleo de Medicina - RS

92. UMC Uberlândia Medical Center - MG

93. Unimed São José do Rio Preto - Espaço Viver Bem - SP

94. UPA STM - PA

Table 2: List of Evaluated Institutions.

\section{Discussion}

True patient engagement in their care remains a great challenge, but at the same time presents an excellent opportunity to change this scenario. One of the difficulties for patient engagement is the absence of a tool that translates in a simple and objective way the user's perception of the health system regarding patient safety [7]. 
According to the Salzburg Statement on Moving Measurement into Action: Global Principles for Measuring Patient Safety: “Despite the innovative approaches to patient safety measurement being developed, tested and used, health care still lacks universally accepted, standard methods for measuring, understanding and improving the safety of patients. Poorly devised or utilized measures currently accessible to the field carry the potential for unintended negative consequences, including overburdening those who collect and analyze metrics or overspending resources on areas with less opportunity for impact" [7].

The Net Promoter Score (NPS) has been used by various industries because it is user-friendly [8]. The theoretical basis of its use is that the tool demonstrates the degree of customer loyalty in relation to the service/company in question. The NPS has been also used by hospitals and health insurance companies, but with a focus on hospitality, hygiene and punctuality [9].

Precisely because it is an easy tool to implement and understand by its user, we believe that its adaptation to evaluate patient safety aspects would be of great value to the entire sector. In addition to expanding its current use in the health market, it would come to contemplate patient safety aspects that remains open. Moreover, as the Salzburg Statement proposes, it would give patients a voice, quantifying their perceptions of safety in manageable numbers.

The option to make these assessments available in a mobile application, brings the possibility of the user receive instructions on patient safety before evaluating the service on screen. In addition, to compiling these assessments in real time dashboard, allows the healthcare managers to use it in their daily routine.

In our study, the users did not receive any instructions how to use the application and how to evaluate the institutions. They were invited to download the app and start to use it. As you can see, during a six months period, 352 downloads were made in 94 different institutions in Brazil, generating 1719 evaluations. As a result, you can find an overall NPS-S of $45 \%$ and all the safety goals, except goal 1 - patient identification, with similar results on the improvement zone. Our understanding is that we have a big opportunity to improve our processes and deliver a better experience for our patients if the institutions start to use the NPS-S to evaluate their safety protocols.

\section{Conclusion}

In this initial experience, the use of the NPS tool adjusted for patient safety aspects, NPS-S, seems to be easy to understand by users and translated their perception of patient safety in manageable scores. More detailed studies are recommended, but we believe that the expansion of the use of NPS-S is promising and can help health institutions to engage patients.

\section{Bibliography}

1. https://patientsafetymovement.org/wp-content/uploads/2019/04/Infographic-Medical-Errors-Long-FT2048B. jpg

2. Makary MA and Daniel M. "Medical Error - the third leading cause of death in US”. British Medical Journal 353 (2016): i2139.

3. Couto RC., et al. "II Anuário da segurança assistencial hospitalar no Brasil". Instituto de estudos de Saúde Suplementar, Belo Horizonte (2018).

4. Frankel A., et al. "A Framework for Safe, Reliable, and Effective Care". White Paper. Cambridge, MA: Institute for Healthcare Improvement and Safe and Reliable Healthcare (2017).

5. Doyle C., et al. "A systematic review of evidence on the links between patient experience and clinical safety and effectiveness". BMJ Open 3 (2013): e001570.

6. Heichheld F. "The One Number You Need". Harvard Business Review December (2003).

7. The Salzburg Statement/ Moving Measurement into Action: Global Principles for Measuring Patient Safety. Institute for Healthcare Improvement and Salzburg Global Seminar (2019).

8. Keiningham T., et al. "A holistic examination of Net Promoter". Journal of Database Marketing and Customer Strategy Management 15 (2008): 79-90.

9. Krol MW., et al. "The Net Promoter Score - an asset to patient experience surveys". Health Expectations 18 (2015): 30993109.

\section{Assets from publication with us}

- Prompt Acknowledgement after receiving the article

- Thorough Double blinded peer review

- Rapid Publication

- Issue of Publication Certificate

- High visibility of your Published work

Website: www.actascientific.com/

Submit Article: www.actascientific.com/submission.php

Email us: editor@actascientific.com

Contact us: +919182824667 